\title{
Mini Review: Reappraisal of Uric Acid in Chronic Kidney Disease
}

\author{
Avi Goldberg $^{\text {a }}$ Fernando Garcia-Arroyo ${ }^{b}$ Fumihiko Sasai ${ }^{c}$ \\ Bernardo Rodriguez-Iturbe ${ }^{b}$ Laura Gabriela Sanchez-Lozada ${ }^{b}$ \\ Miguel A. Lanaspac Richard J. Johnson ${ }^{c, d}$ \\ ${ }^{a}$ Clalit Health Services, Hebrew University of Jerusalem, Jerusalem, Israel; bepartment of Cardio-Renal \\ Physiopathology, INC Ignacio Chávez, Mexico City, Mexico; 'Division of Renal Diseases and Hypertension, University

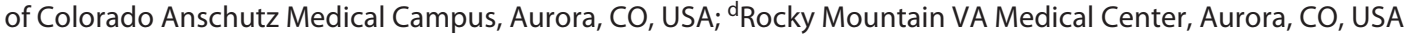

\section{Keywords}

Hyperuricemia $\cdot$ Mendelian randomization · Metabolic syndrome · Gout

\begin{abstract}
Hyperuricemia predicts the development of chronic kidney disease (CKD) and metabolic complications, but whether it has a causal role has been controversial. This is especially true given the 2 recently conducted randomized controlled trials that failed to show a benefit of lowering uric acid in type 1 diabetes-associated CKD and subjects with stage 3-4 CKD. While these studies suggest that use of urate-lowering drugs in unselected patients is unlikely to slow the progression of CKD, there are subsets of subjects with CKD where reducing uric acid synthesis may be beneficial. This may be the case in patients with gout, hyperuricemia (especially associated with increased production), and urate crystalluria. Here, we discuss the evidence and propose that future clinical trials targeting these specific subgroups should be performed.

(c) 2021 S. Karger AG, Basel
\end{abstract}

\section{Introduction}

The role of uric acid in chronic kidney disease (CKD) has been a controversial topic for decades. Studies supporting a role for uric acid as an important mediator of CKD are extensive. Epidemiological studies have consistently found that elevated serum uric acid is a predictor for the development of CKD, and early studies documented reduced kidney function in approximately $50 \%$ of subjects with gout, and histologic injury (consisting of glomerulosclerosis, tubulointerstitial fibrosis, and arteriolosclerosis) was found in over $90 \%$ of autopsies of patients with gout $[1,2]$. Experimentally raising uric acid could both cause low-grade kidney damage and accelerate established CKD $[3,4]$. Potential mechanisms were also identified driven by both crystalline and noncrystalline uric acid that included both hemodynamic effects (increasing glomerular hydrostatic pressure and reducing blood flow) and nonhemodynamic pathways (stimulating inflammation, activating vasoconstrictive pathways, blocking endogenous vasodilatory pathways, and

Correspondence to:

Richard J Johnson, richard.johnson@ @uanschutz.edu 
stimulating vascular cell proliferation and inhibiting endothelial function) [5-9]. Uric acid was also found to affect cellular metabolism by causing mitochondrial oxidative stress, inhibiting mitochondrial function, and altering cellular energetics $[10,11]$. Indeed, studies suggested uric acid was not only important in kidney disease but also in driving acute kidney injury, hypertension, metabolic syndrome, and diabetes $[12,13]$. Uric acid has also been proposed to have potential roles in other conditions, including cancer, behavioral disorders, and Alzheimer's disease [14-16].

There are also studies that have challenged the pathogenic role of uric acid in CKD. A central argument is that the association of uric acid with CKD is expected because the kidney has a major role in excreting uric acid, and so as kidney function fails, serum uric acid will rise. The finding that an elevated serum uric acid may predict the development of CKD may simply reflect that subtle kidney damage was already present. Indeed, once individuals have CKD, a high uric acid often does not independently predict progression of CKD [1]. Furthermore, a sophisticated method known as Mendelian randomization was used to identify genetic polymorphisms in genes that affect serum uric acid levels, and then a genetic score was developed that could affect approximately $5-7 \%$ of the variation in serum uric acid levels. When such scores were developed, population studies could determine if those who have scores favoring higher serum uric acid levels are at risk for CKD or other metabolic disorders. When these types of analyses were performed, the vast majority concluded that while genetic polymorphisms could predict gout, they did not predict the development of CKD or other conditions including hypertension, metabolic syndrome, or diabetes [17-20]. More recently, an experimental model of hyperuricemia was reported in which kidney disease also did not develop, challenging the experimental studies [21]. Indeed, while it is accepted that crystalline uric acid is pro-inflammatory, there has even been the suggestion that soluble uric acid may be beneficial, as it can function as an antioxidant [22]. Supporting this idea, there have been several clinical studies suggesting that the acute infusion of uric acid (or its precursor inosine) may confer some benefits in neurological disorders such as Parkinson's disease and acute ischemic stroke [23, 24].

It has been largely thought that the best way to resolve the question of whether uric acid has a causal role in CKD would be to perform clinical trials to determine if lowering uric acid can slow the progression of CKD. Initial studies were positive $[25,26]$, but many of these studies were small, lacked the use of a placebo, and were more consistent with pilot studies. One randomized, placebocontrolled study from India showed a remarkable slowing of CKD with febuxostat (a xanthine oxidase inhibitor) [27], but another larger but similarly designed study from Japan showed no benefit (the FEATHER study) [28]. Our group suggested that the reason might be because the control group in the FEATHER study showed minimal worsening of kidney disease over the 2 years of the study $\left(-0.47 \mathrm{~mL} / \mathrm{min} / 1.73 \mathrm{~m}^{2} \mathrm{eGFR}\right)$, and that this prevented the ability for a study drug to show significant benefit even if it were effective [29]. Indeed, when we reviewed over 20 clinical trials that had been published, a benefit was observed in all of the studies in which significant progression occurred in the control group, and the negative studies were limited to studies viewed as noninterpretable due to the fact that the kidney function in the control group remained stable [29].

Then, in June 2020, 2 large randomized, double-blind, placebo-controlled trials were published (Table 1) [30, 31]. The first study, known as the Preventing Early Renal Loss in Diabetes (PERL) trial, evaluated type 1 diabetics with mild to moderate CKD (stages 2 and 3) with evidence for worsening kidney function. These subjects were normotensive, with around $90 \%$ on renin angiotensin system (RAS) blockers, and were randomized to allopurinol or placebo over 3 years. The study even included measurement of true GFR using the iohexol method. The second study, known as the Controlled Trial of Slowing of Kidney Disease Progression from the Inhibition of Xanthine Oxidase (CKD-FIX), studied the effect of allopurinol to slow renal progression in subjects with modest to severe CKD (stages 3 and 4 ) of all types (including $45 \%$ who were diabetic). Both studies reported no benefit of allopurinol to slow CKD despite significant worsening of kidney function in the control groups. Indeed, there was a tendency for higher mortality in the allopurinol-treated groups when the studies were combined.

The strength of these 2 studies includes the large number of patients studied, the rigorous design, the relatively long follow-up, the low risk of bias, and the finding of significant worsening of kidney function in the control group (Table 1). There were also weaknesses noted, including the high dropout rate (which affected the final analysis as these were intention-to-treat studies), the inclusion of individuals with normal uric acid levels, and the exclusion of subjects with gout (Table 1). Nevertheless, the findings of these 2 studies suggested the conclusion that "urate is not causally implicated in the risk for CKD progression in most patients regardless of baseline risk," and that further clinical trials are not warranted [32]. 
Table 1. Strengths and weaknesses in the CKD-FIX and PERL studies

\begin{tabular}{|c|c|c|c|c|c|}
\hline Study & Characteristics & Participants (n) & Outcome $(\triangle G F R)$ & Strengths & Weakness \\
\hline \multirow[t]{4}{*}{ CKD-FIX } & \multirow{4}{*}{$\begin{array}{l}\text { CKD (stage } 3 \text { or } 4,45.5 \\
\text { diabetic, proteinuric, or } \\
\text { with falling GFR in the } \\
\text { prior year, any uric acid) }\end{array}$} & Screened $(11,998)$ & -3.3 versus $-3.2 \mathrm{~mL} / \mathrm{min} / 1.73 \mathrm{~m}^{2}$ & Randomized, double-blind & Excluded gout \\
\hline & & Entered (369) & Per year, allopurinol versus placebo & Placebo controlled & Included normouricemia \\
\hline & & Dropped out (93) & & Two years of follow-up & High dropout rate (25\%) \\
\hline & & Final (276) & & Intention-to-treat analysis & \\
\hline \multirow[t]{5}{*}{ PERL } & \multirow{5}{*}{$\begin{array}{l}\text { Type } 1 \text { diabetes with } \\
\text { CKD stage } 2 \text { or } 3 \text {, uric } \\
\text { acid } \geq 4.5 \mathrm{mg} / \mathrm{dL}\end{array}$} & Screened $(1,625)$ & -3 versus $-2.5 \mathrm{~mL} / \mathrm{min} / 1.73 \mathrm{~m}^{2}$ & Randomized, double-blind & Excluded gout \\
\hline & & Entered (530) & Per year, allopurinol versus placebo & Placebo controlled & Included normouricemia \\
\hline & & Dropped out (108) & & Three years of follow-up & High dropout rate (20\%) \\
\hline & & Final (422) & & True GFR measured (iohexol) & \\
\hline & & & & Intention-to-treat analysis & \\
\hline
\end{tabular}

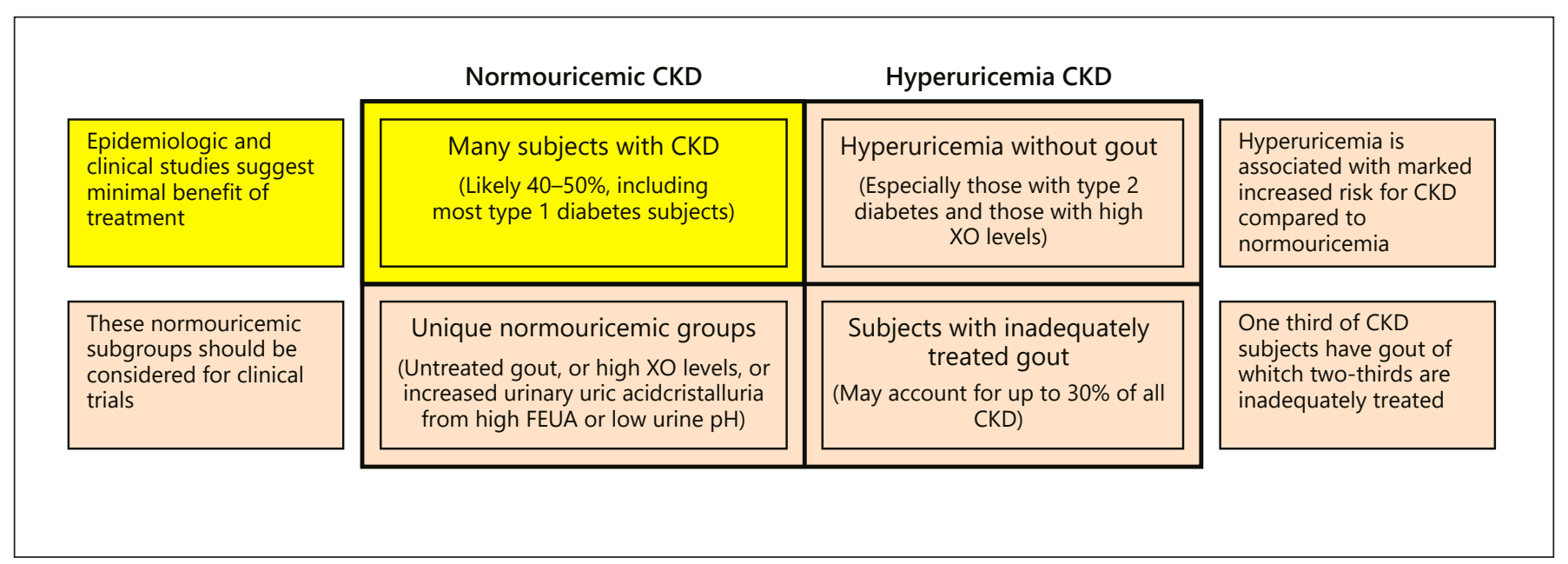

Fig. 1. CKD and uric acid: subpopulations to consider for clinical trials. We do not recommend uric acid-lowering treatment for normouricemic subjects with CKD that include the majority of type 1 diabetic subjects (yellow blocked section) based on the results of the CKD-FIX and PERL studies. This also includes many subjects with CKD who may have hypertension or proteinuria. However, there are certain subsets of CKD for which we would

But, are there no caveats in this conclusion? One potential explanation is that uric acid is causal, but that the use of RAS inhibitors may be effectively mimicking the effect of lowering uric acid, as there are experimental and clinical studies that show that many of the effects of hyperuricemia appear to act by stimulation of the RAS [3335]. If true, however, this would not provide any rationale for lowering of uric acid since RAS inhibition is standard fare in subjects with CKD. recommend clinical trials (brown boxes). This would include subjects with gout, subjects with hyperuricemia (especially those with type 2 diabetes or those with high plasma xanthine oxidase levels), and those relatively unique normouricemic subjects with untreated gout, high plasma XO levels, or with evidence of urate crystalluria (with low urine $\mathrm{pH}$ or high fractional excretion of uric acid). $\mathrm{CKD}$, chronic kidney disease.

There is another, important question. Lowering uric acid in an average patient with advanced CKD may not be of benefit, and lowering uric acid in an average type 1 diabetic subject with CKD may not show overall benefit, but can we generalize these studies to all patients with $\mathrm{CKD}$ ? Here, we discuss specific groups where we suggest clinical trials for lowering uric acid to preserve kidney function are needed (Fig. 1). 


\section{Subgroups of CKD Where Lowering Uric Acid May Be of Benefit}

\section{Gout and CKD}

Gout is common in subjects with CKD, being present in about one-third of subjects with CKD stage 3 or 4 [36]. Unfortunately, the vast majority are either not treated or inadequately treated, and hence only $25 \%$ of subjects with gout and CKD have serum uric acid levels at the target goal of $6 \mathrm{mg} / \mathrm{dL}$ or less [37]. The PERL and CKD-FIX studies excluded all subjects with a history of gout, even if it was remote, assuming that they would already be on treatment for their arthritis. Therefore, the conclusions of these studies do not apply to patients with gout in whom lowering uric acid might theoretically be the most beneficial at reducing the progression of kidney disease.

Subjects with CKD and gout have more tophi than gouty subjects with normal kidney function (6-fold greater in stage 3 CKD) [38], suggesting they carry higher risk for extra-articular crystal deposits. Recently, it has been recognized that urate crystals can deposit in many locations, including the kidney, blood vessels, and spine [39]. One study reported that urate crystals are present in the aorta or coronary vessels in $80 \%$ of subjects with gout [40], where it can localize to plaques [41]. Urate crystals may also act as a nidus for calcification [42], and many urate deposits correspond to sites of vascular calcification [40]. Urate crystals also deposit in the kidney, and one study suggests this may occur in up to one-third of subjects with gout [43]. Finally, urate crystals can also occur in the blood vessels and kidneys of subjects with hyperuricemia in the absence of gout, although it is much less frequent than that which occurs in subjects with gout [40]. Thus, it is quite possible that subjects with a history of gout and CKD might represent a unique group in which lowering uric acid might benefit not simply reducing gout attacks, but with potential benefits on CKD and vascular and heart disease.

\section{Hyperuricemia (Especially When Unrelated to Renal Retention)}

The CKD-FIX and PERL studies were not designed to study the benefit of treating hyperuricemia; therefore, both trials included subjects with normal uric acid levels. The risk for developing CKD, however, increases dramatically after serum uric acid levels reach the hyperuricemic range (typically at around $8 \mathrm{mg} / \mathrm{dL}$ ), especially in women [44-46]. For example, in one population-based study, the risk for ESKD was 1.22 for men without hyperuricemia and 4.64 for men with hyperuricemia and 0.87 for women without hyperuricemia and 9.03 for women with hyperuricemia [44]. In the PERL study, the mean serum uric acid was in the normal range $(6.1 \mathrm{mg} / \mathrm{dL})$, documenting that the trial largely included normouricemic individuals. Any entry serum uric acid level was acceptable for the CKD-FIX trial, and since approximately half of the CKD subjects are hyperuricemic at the time of dialysis initiation [47], it is likely that there were significant numbers of patients with normal uric acid levels despite the mean uric acid at entry being in the hyperuricemic range.

It is also possible that the type of hyperuricemia may be important. Many of the metabolic effects of uric acid appear to be mediated by intracellular uric acid levels. Factors that stimulate the production of uric acid, such as fructose, increase intracellular uric acid that then secondarily increases circulating (extracellular) uric acid [48, 49]. This is then associated with a variety of metabolic effects, including the stimulation of oxidative stress, inflammation, and mitochondrial dysfunction [11, 50, 51]. Similarly, increasing extracellular uric acid can also lead to an increase in intracellular uric acid associated with metabolic activation [52]. However, recent studies suggest that high levels of extracellular uric acid may turn down the urate transport system reducing its ability to increase intracellular uric acid, at least in the monocyte [53].

This would suggest that hyperuricemia due to increased production might be more likely to mediate inflammatory effects compared to passive retention of uric acid such as from worsening kidney function. This might explain why hyperuricemia in the setting of normal renal function (which may be more likely from increased production) predicts the development of CKD while elevated uric acid in subjects with preexisting CKD does not predict worsening of kidney function [1].

One indirect way to assess intracellular uric acid is by measuring plasma xanthine oxidase activity by enzyme activity assays or Western blot analysis. Indeed, plasma xanthine oxidase activity correlates with metabolic disorders better than serum uric acid [54]. Plasma xanthine oxidase activity has been linked with insulin resistance even when serum uric acid levels are low $(<4 \mathrm{mg} / \mathrm{dL})$ [55]. Plasma xanthine oxidase activity is high in many subjects with $\mathrm{CKD}$, but it does not correlate well with serum uric acid [56]. Interestingly, subjects with CKD and elevated plasma xanthine oxidase activity have the greatest risk for developing cardiovascular events [56]. Thus, future studies may need to specifically test whether lowering uric acid benefits CKD subjects with hyperuricemia associated with or without elevated plasma xanthine oxidase activity. 


\section{Elevated Fractional Excretion of Uric Acid}

While the role of uric acid has generally focused on serum and intracellular uric acid, elevations in urinary uric acid may also predispose to kidney injury via crystalline and noncrystalline effects. The best example is tumor lysis syndrome in which massive production of uric acid leads to marked hyperuricemia with urate crystallization in the urinary tubules, leading to local obstruction and inflammation and an acute kidney injury (AKI) $[57,58]$. Similar types of AKI have been reported following rhabdomyolysis, grand mal seizures, and cardiovascular surgery (especially in children). Urate crystalluria may also occur with heat stress and could potentially have a role in the CKD of unknown etiology observed in Central America [59]. AKI can also occur with the acute administration of uricosuric agents in hyperuricemic individuals [60]. Finally, AKI can occur in hypouricemic individuals with genetic absence of key urate transporters, such as SLC2A9 or URAT1 [61]. In the latter cases, this usually occurs after exercise in which uricosuria is worse and dehydration may be more common. One study reported that administering xanthine oxidase inhibitors to a hypouricemic individual with recurrent AKI led to a resolution of the AKI [62]. This is an example of how uric acid could be causing AKI even when the serum uric acid is $<2 \mathrm{mg} / \mathrm{dL}$.

Therefore, uric acid could potentially be causing CKD in some patients through a crystalluria mechanism. Indeed, we found that administering bicarbonate to type 1 diabetic subjects could alkalinize the urine, reduce urate crystals, and decrease tubular biomarkers of injury [63].

Today, numerous studies are evaluating the effect of bicarbonate supplementation as a means to slow CKD progression [64]. While the focus has been on correcting metabolic acidosis, a simpler mechanism might be that it is alkalinizing the urine and decreasing urate crystal formation. Indeed, acid urine $\mathrm{pH}$ is now recognized as a risk factor for CKD [65]. It would be of interest if the benefit of bicarbonate administration was primarily in subjects who have acid urine and high urinary uric acid levels. Again, a clinical study investigating this might be warranted.

\section{Hyperuricemia Associated with Nonalcoholic Liver \\ Disease or Type 2 Diabetes}

Experimental studies suggest that intake of added sugars containing fructose have a major role in driving both nonalcoholic fatty liver disease (NAFLD) and type 2 diabetes, and in both conditions, there is evidence that elevations in intracellular uric acid have a contributory role [66, 67]. Hyperuricemia is also a predictor for CKD in subjects with type 2 diabetes [68]. Likewise, the prevalence of CKD is higher in NAFLD patients, and a relationship between the severity of NAFLD and the presence of decreased eGFR or proteinuria has been reported [69]. Moreover, incident CKD is also common in patients having NAFLD diagnosed by ultrasound at baseline [70]. Xanthine oxidase is shed into the circulation mainly from liver cells, and its serum activity is increased in NAFLD patients [71]. These observations raise the possibility that hyperuricemia subjects with type 2 diabetes or NAFLD may benefit from XO inhibitors to prevent or slow CKD progression.

\section{Biomarkers and Mendelian Randomization}

Today, we tend to assess the role of uric acid in disease by evaluating serum uric acid, and while it generally correlates with gout, metabolic disease, and kidney disease, we should recognize that serum uric acid level may not reflect the systemic urate burden/pool nor the intracellular uric acid level. As mentioned, experimental studies suggest that it is the intracellular uric acid level - better reflected by plasma xanthine oxidase activity - that drives most metabolic and renal diseases, and it is the fractional excretion of uric acid and the urinary $\mathrm{pH}$ that dictate urinary crystallization and acute kidney injury in crystal-dependent models of injury.

Even gout is imperfectly predicted by serum uric acid level. The classic teaching is that the risk for gout occurs when uric acid levels are $>6.8 \mathrm{mg} / \mathrm{dL}$ because this represents the saturation concentration when uric acid crystallizes in water containing $140 \mathrm{mM}$ sodium at $\mathrm{pH} 7.4$ [72]. Nevertheless, of the 30 million people in the USA with serum uric acid levels above this concentration, only 9 million have gout [73]. Thus, one can have super-saturable uric acid concentrations without having gout. Likewise, one can have gout attacks despite uric acid levels being $<6 \mathrm{mg} / \mathrm{dL}[74,75]$. One possibility is that serum uric acid was high, but it was lower when measured during an acute gout attack due to transient increased urinary excretion [76]. There is also often an inappropriate reliance on fasting serum uric acid, as this may not accurately reflect postprandial levels following intake of purines or fructose or with the acute effects of exercise or heat $[59,77,78]$. Despite these concerns, some subjects always have normal uric acid levels when tested on multiple occasions despite suffering from gout [74].

Thus, while generally one can ascribe gout as a condition associated with an elevated serum uric acid, a high serum uric acid is not requisite for gout nor does a low serum uric acid exclude it. It is similar to the story of the sugar cubes. If one sees a series of white sugar cubes, one cannot say that there are only white sugar cubes, but if one sees a series of 
white sugar cubes and 1 brown cube, one can say with certainty that sugar cubes do not always have to be white. The implication is that serum uric acid is not directly causal of gout, for one can have high uric acid levels without gout and low uric acid levels with gout. Rather, serum uric acid is a risk factor, and the true causal risk factor is the net effect of the various factors driving urate crystallization that are important in determining whether a gout attack occurs.

A problem with the Mendelian randomization studies is that they assume the serum uric acid is not only the most important uric acid marker but also that it represents causality when it relates to uric acid disorders. While serum uric acid may commonly reflect intracellular uric acid, we know from the earlier discussions that this does not need to be true.

Mendelian randomization studies also depend on the genetic score based on gene polymorphisms that influence serum uric acid. Most of these genes influence transport in and out of cells rather than affecting uric acid production. One of the strongest genetic polymorphisms involves SLC2A9, which has opposing functions depending on where it is expressed in the body, such that it eliminates serum uric acid via the gut but increases serum uric acid via the kidney [79]. This is why knocking out SLC2A9 in the kidney, or systemically, causes massive uricosuria and hypouricemia [80], but knocking out SCL2A9 in the liver causes hyperuricemia [79]. Interestingly, there is evidence that the metabolic effects of fructose and uric acid primarily result from metabolism in the liver [81]. Evidence supporting this comes from the gut-specific SLC2A9 knockout that develops metabolic abnormalities (increased body fat, hyperinsulinemia, hypertriglyceridemia, and elevated blood pressure) [79]. Thus, a polymorphism in SLC2A9 that raises serum uric acid via its effects on the kidney would not be expected to cause metabolic effects since there would be enhanced excretion of uric acid in the gut, reducing portal vein and hepatic levels. This could account for the negative Mendelian studies
$[17,20,82]$. Nevertheless, more recently, a number of Mendelian randomization studies have been able to associate genetic uric acid scores with a variety of outcomes, including hypertension, cardiovascular events, and kidney disease [83-86].

In summary, while the PERL and CKD-FIX studies have given important information, it is not a time to abandon all studies on the role of uric acid in CKD. Rather, it is an exciting time to test whether targeting specific subpopulations to test whether lowering uric acid in these groups can provide benefit (Fig. 1). Among these specific subgroups are the patients with gout, with hyperuricemia, with high plasma xanthine oxidase, and with high urinary excretion of uric acid.

\section{Conflict of Interest Statement}

R.J.J. has received honoraria from Horizon Pharma and Danone, has stocks with XORTX Therapeutics, and has equity with Colorado Research Partners LLC (CRP). L.G.S.L. and M.A.L. also have equity with CRP. No other conflicts exist.

\section{Funding Sources}

This study was supported in part by VA Merit(BXI01BX004501) (R.J.J.), NIH DK125351 (R.J.J.), and DK121496 (R.J.J. and M.A.L.).

\section{Author Contributions}

A.G. and R.J.J. wrote the initial draft. F.G.-A., F.S., B.R.-I., L.G.S.-L., and M.A.L. provided insights and suggestions for modification of the manuscript and assisted with the figure and table.

\section{Note Added in Proof}

Dr. Bernardo Rodriguez-Iturbe is also with the Instituto Nacional de Cencias Médicas y Nutrición "Salvador Zubirán", Department of Nephrology, Mexico City, Mexico.

\section{References}

1 Johnson RJ, Nakagawa T, Jalal D, Sánchez-Lozada LG, Kang DH, Ritz E. Uric acid and chronic kidney disease: which is chasing which? Nephrol Dial Transplant. 2013;28:2221-8.

2 Talbott JH, Terplan KL. The kidney in gout. Medicine. 1960;39:405-67.

3 Mazzali M, Hughes J, Kim YG, Jefferson JA, Kang DH, Gordon KL, et al. Elevated uric acid increases blood pressure in the rat by a novel crystal-independent mechanism. Hypertension. 2001;38:1101-6.
4 Kang DH, Nakagawa T, Feng L, Watanabe S, Han L, Mazzali M, et al. A role for uric acid in the progression of renal disease. J Am Soc Nephrol. 2002;13:2888-97.

5 Yu MA, Sánchez-Lozada LG, Johnson RJ, Kang DH. Oxidative stress with an activation of the renin-angiotensin system in human vascular endothelial cells as a novel mechanism of uric acid-induced endothelial dysfunction. J Hypertens. 2010;28: 1234-42.
6 Sanchez-Lozada LG, Tapia E, Santamaria J, Avila-Casado C, Soto V, Nepomuceno T, et al. Mild hyperuricemia induces vasoconstriction and maintains glomerular hypertension in normal and remnant kidney rats. Kidney Int. 2005;67:237-47.

7 Kim SM, Lee SH, Kim YG, Kim SY, Seo JW, Choi YW, et al. Hyperuricemia-induced NLRP3 activation of macrophages contributes to the progression of diabetic nephropathy. Am Physiol Renal Physiol. 2015;308:F993-F1003. 
8 Xiao J, Zhang XL, Fu C, Han R, Chen W, Lu Y, et al. Soluble uric acid increases NALP3 inflammasome and interleukin- $1 \beta$ expression in human primary renal proximal tubule epithelial cells through the Toll-like receptor 4-mediated pathway. Int J Mol Med. 2015;35:1347-54.

9 Khosla UM, Zharikov S, Finch JL, Nakagawa $\mathrm{T}$, Roncal C, Mu W, et al. Hyperuricemia induces endothelial dysfunction. Kidney Int. 2005;67:1739-42.

10 Sanchez-Lozada LG, Lanaspa MA, CristobalGarcia M, Garcia-Arroyo F, Soto V, Cruz-Robles $\mathrm{D}$, et al. Uric acid-induced endothelial dysfunction is associated with mitochondrial alterations and decreased intracellular ATP concentrations. Nephron Exp Nephrol. 2012; 121:e71-8.

11 Lanaspa MA, Sanchez-Lozada LG, Choi YJ, Cicerchi C, Kanbay M, Roncal-Jimenez CA, et al. Uric acid induces hepatic steatosis by generation of mitochondrial oxidative stress: potential role in fructose-dependent and -independent fatty liver. J Biol Chem. 2012;287: 40732-44.

12 Ejaz AA, Nakagawa T, Kanbay M, Kuwabara M, Kumar A, Garcia Arroyo FE, et al. Hyperuricemia in kidney disease: a major risk factor for cardiovascular events, vascular calcification, and renal damage. Semin Nephrol. 2020; 40(6):574-85.

13 Feig DI, Madero M, Jalal DI, Sanchez-Lozada LG, Johnson RJ. Uric acid and the origins of hypertension. J Pediatr. 2013;162:896-902.

14 Nakagawa T, Lanaspa MA, Millan IS, Fini M, Rivard CJ, Sanchez-Lozada LG, et al. Fructose contributes to the Warburg effect for cancer growth. Cancer Metab. 2020;8:16.

15 Fini MA, Elias A, Johnson RJ, Wright RM Contribution of uric acid to cancer risk, recurrence, and mortality. Clin Transl Med. 2012;1:16

16 Johnson RJ, Gomez-Pinilla F, Nagel M, Nakagawa T, Rodriguez-Iturbe B, Sanchez-Lozada LG, et al. Cerebral fructose metabolism as a potential mechanism driving Alzheimer's disease. Front Aging Neurosci. 2020;12:560865.

17 Jordan DM, Choi HK, Verbanck M, Topless R, Won HH, Nadkarni G, et al. No causal effects of serum urate levels on the risk of chronic kidney disease: a Mendelian randomization study. PLoS Med. 2019;16:e1002725.

18 Pfister R, Barnes D, Luben R, Forouhi NG, Bochud M, Khaw KT, et al. No evidence for a causal link between uric acid and type 2 diabetes: a Mendelian randomisation approach. Diabetologia. 2011;54:2561-9.

19 Sedaghat S, Pazoki R, Uitterlinden AG, Hofman A, Stricker BH, Ikram MA, et al. Association of uric acid genetic risk score with blood pressure: the Rotterdam study. Hypertension. 2014;64:1061-6.

20 Yang Q, Köttgen A, Dehghan A, Smith AV, Glazer NL, Chen MH, et al. Multiple genetic loci influence serum urate levels and their relationship with gout and cardiovascular disease risk factors. Circ Cardiovasc Genet. 2010; 3:523-30.
21 Sellmayr M, Hernandez Petzsche MR, Ma Q, Kruger N, Liapis H, Brink A, et al. Only hyperuricemia with crystalluria, but not asymptomatic hyperuricemia, drives progression of chronic kidney disease. J Am Soc Nephrol. 2020;31(12):2773-92.

22 Ames BN, Cathcart R, Schwiers E, Hochstein P. Uric acid provides an antioxidant defense in humans against oxidant- and radicalcaused aging and cancer: a hypothesis. Proc Natl Acad Sci USA. 1981;78:6858-62.

23 Schwarzschild MA, Macklin EA, Bakshi R, Battacharyya S, Logan R, Espay AJ, et al. Sex differences by design and outcome in the Safety of urate elevation in PD (SURE-PD) trial. Neurology. 2019;93:e1328-38.

24 Chamorro A, Amaro S, Castellanos M, Gomis M, Urra X, Blasco J, et al. Planas AM, investigators U-I: uric acid therapy improves the outcomes of stroke patients treated with intravenous tissue plasminogen activator and mechanical thrombectomy. Int J Stroke. 2017; 12:377-82.

25 Siu YP, Leung KT, Tong MK, Kwan TH. Use of allopurinol in slowing the progression of renal disease through its ability to lower serum uric acid level. Am J Kidney Dis. 2006;47: $51-9$

26 Goicoechea M, Garcia de Vinuesa S, Verdalles U, Verde E, Macias N, Santos A, et al. Allopurinol and progression of CKD and cardiovascular events: long-term follow-up of a randomized clinical trial. Am J Kidney Dis. 2015; 65(4):543-9.

27 Sircar D, Chatterjee S, Waikhom R, Golay V, Raychaudhury A, Chatterjee S, et al. Efficacy of febuxostat for slowing the GFR decline in patients with CKD and asymptomatic hyperuricemia: a 6-month, double-blind, randomized, placebo-controlled trial. Am J Kidney Dis. 2015;66:945-50.

28 Kimura K, Hosoya $\mathrm{T}$, Uchida S, Inaba $\mathrm{M}$, Makino H, Maruyama S, et al. Febuxostat therapy for patients with stage $3 \mathrm{CKD}$ and asymptomatic hyperuricemia: a randomized trial. Am J Kidney Dis. 2018;72:798-810.

29 Sato Y, Feig DI, Stack AG, Kang DH, Lanaspa MA, Ejaz AA, et al. The case for uric acid-lowering treatment in patients with hyperuricaemia and CKD. Nat Rev Nephrol. 2019;15:767-75.

30 Doria A, Galecki AT, Spino C, Pop-Busui R, Cherney DZ, Lingvay I, et al. Serum urate lowering with allopurinol and kidney function in type 1 diabetes. N Engl J Med. 2020; 382:2493-503.

31 Badve SV, Pascoe EM, Tiku A, Boudville N, Brown FG, Cass A, et al. Effects of allopurinol on the progression of chronic kidney disease. N Engl J Med. 2020;382:2504-13.

32 Pyne L, Walsh M. Allopurinol: good for gout but not for preventing loss of kidney function. Am J Kidney Dis. 2021;77(3):459-61.

33 Mazzali M, Kanellis J, Han L, Feng L, Xia YY, Chen Q, et al. Hyperuricemia induces a primary renal arteriolopathy in rats by a blood pressure-independent mechanism. Am J Physiol Renal Physiol. 2002;282:F991-7.
34 Talaat KM, El-Sheikh AR. The effect of mild hyperuricemia on urinary transforming growth factor beta and the progression of chronic kidney disease. Am J Nephrol. 2007; 27(5):435-40.

35 Feig DI, Soletsky B, Johnson RJ. Effect of allopurinol on blood pressure of adolescents with newly diagnosed essential hypertension: a randomized trial. JAMA. 2008;300:924-32.

36 Krishnan E. Reduced glomerular function and prevalence of gout: NHANES 2009-10. PLoS One. 2012;7:e50046.

37 Fuldeore MJ, Riedel AA, Zarotsky V, Pandya BJ, Dabbous O, Krishnan E. Chronic kidney disease in gout in a managed care setting. BMC Nephrol. 2011;12:36.

38 Dalbeth N, House ME, Horne A, Taylor WJ. Reduced creatinine clearance is associated with early development of subcutaneous tophi in people with gout. BMC Musculoskelet Disord. 2013;14:363.

39 Khanna P, Johnson RJ, Marder B, LaMoreaux B, Kumar A. Systemic urate deposition: an unrecognized complication of gout? J Clin Med. 2020;9.

40 Klauser AS, Halpern EJ, Strobl S, Gruber J, Feuchtner G, Bellmann-Weiler R, et al. Dualenergy computed tomography detection of cardiovascular monosodium urate deposits in patients with gout. JAMA Cardiol. 2019;4: 1019-28.

41 Patetsios P, Song M, Shutze WP, Pappas C, Rodino W, Ramirez JA, et al. Identification of uric acid and xanthine oxidase in atherosclerotic plaque. Am J Cardiol. 2001;88:188-A6.

42 Coe FL, Raisen L. Allopurinol treatment of uric-acid disorders in calcium-stone formers. Lancet. 1973;1:129-31.

43 Bardin T, Nguyen QD, Tran KM, Le NH Richette P, et al. Diffuse hyperechoic renal medulla pattern in gout: a cross-sectional study of 502 patients. Kidney Int. 2021;99(1): 218-26.

44 Iseki K, Ikemiya Y, Inoue T, Iseki C, Kinjo K, Takishita S. Significance of hyperuricemia as a risk factor for developing ESRD in a screened cohort. Am J Kidney Dis. 2004;44:642-50.

45 Iseki K, Iseki C, Ikemiya Y, Fukiyama K. Risk of developing end-stage renal disease in a cohort of mass screening. Kidney Int. 1996;49: 800-5.

46 Obermayr RP, Temml C, Gutjahr G, Knechtelsdorfer M, Oberbauer R, Klauser-Braun R. Elevated uric acid increases the risk for kidney disease. J Am Soc Nephrol. 2008;19: 2407-13.

47 Suliman ME, Johnson RJ, García-López E, Qureshi AR, Molinaei H, Carrero JJ, et al. Jshaped mortality relationship for uric acid in CKD. Am J Kidney Dis. 2006;48:761-71.

48 Kim KM, Henderson GN, Ouyang X, Frye RF, Sautin YY, Feig DI, et al. A sensitive and specific liquid chromatography-tandem mass spectrometry method for the determination of intracellular and extracellular uric acid. J Chromatogr B Analyt Technol Biomed Life Sci. 2009;877:2032-8. 
49 van den Berghe G, Bronfman M, Vanneste R, Hers HG. The mechanism of adenosine triphosphate depletion in the liver after a load of fructose. A kinetic study of liver adenylate deaminase. Biochem J. 1977;162:601-9.

50 Glushakova O, Kosugi T, Roncal C, Mu W, Heinig M, Cirillo P, et al. Fructose induces the inflammatory molecule ICAM-1 in endothelial cells. J Am Soc Nephrol. 2008;19:1712-20.

51 Cirillo P, Gersch MS, Mu W, Scherer PM, Kim KM, Gesualdo L, et al. Ketohexokinasedependent metabolism of fructose induces proinflammatory mediators in proximal tubular cells. J Am Soc Nephrol. 2009;20:54553.

52 Sautin YY, Nakagawa T, Zharikov S, Johnson RJ. Adverse effects of the classic antioxidant uric acid in adipocytes: NADPH oxidase-mediated oxidative/nitrosative stress. Am J Physiol Cell Physiol. 2007;293:C584-96.

$53 \mathrm{Ma}$ Q, Honarpisheh M, Li C, Sellmayr M, Lindenmeyer M, Böhland C, et al. Soluble uric acid is an intrinsic negative regulator of monocyte activation in monosodium urate crystal-induced tissue inflammation. J Immunol. 2020;205:789-800.

54 Furuhashi M, Matsumoto M, Tanaka M, Moniwa N, Murase T, Nakamura T, et al. Plasma xanthine oxidoreductase activity as a novel biomarker of metabolic disorders in a general population. Circ J. 2018;82:1892-9.

55 Furuhashi M, Mori K, Tanaka M, Maeda T, Matsumoto M, Murase T, et al. Unexpected high plasma xanthine oxidoreductase activity in female subjects with low levels of uric acid. Endocr J. 2018;65:1083-92.

56 Gondouin B, Jourde-Chiche N, Sallee M, Dou L, Cerini C, Loundou A, et al. Plasma xanthine oxidase activity is predictive of cardiovascular disease in patients with chronic kidney disease, independently of uric acid levels Nephron. 2015;131:167-74.

57 Shimada M, Johnson RJ, May WS Jr, Lingegowda V, Sood P, Nakagawa T, et al. A novel role for uric acid in acute kidney injury associated with tumour lysis syndrome. Nephrol Dial Transplant. 2009;24:2960-4.

58 Kim YG, Huang XR, Suga S, Mazzali M, Tang $\mathrm{D}$, Metz C, et al. Involvement of macrophage migration inhibitory factor (MIF) in experimental uric acid nephropathy. Mol Med. 2000;6:837-48.

59 Roncal-Jimenez C, García-Trabanino R, Barregard L, Lanaspa MA, Wesseling C, Harra T, et al. Heat stress nephropathy from exerciseinduced uric acid crystalluria: a perspective on mesoamerican nephropathy. Am J Kidney Dis. 2016;67:20-30.
60 Sanchez-Nino MD, Zheng-Lin B, Valino-Rivas L, Sanz AB, Ramos AM, Luno J, et al. Lesinurad: what the nephrologist should know. Clin Kidney J. 2017;10:679-87.

61 Shen H, Feng C, Jin X, Mao J, Fu H, Gu W, et al. Recurrent exercise-induced acute kidney injury by idiopathic renal hypouricemia with a novel mutation in the SLC2A9 gene and literature review. BMC Pediatr. 2014;14:73.

62 Bhasin B, Stiburkova B, De Castro-Pretelt M, Beck N, Bodurtha JN, Atta MG. Hereditary renal hypouricemia: a new role for allopurinol? Am J Med. 2014;127:e3-4.

63 Bjornstad P, Maahs DM, Roncal CA, SnellBergeon JK, Shah VN, Milagres T, et al. Role of bicarbonate supplementation on urine uric acid crystals and diabetic tubulopathy in adults with type 1 diabetes. Diabetes Obes Metab. 2018;20:1776-80.

64 Goraya N, Wesson DE. Clinical evidence that treatment of metabolic acidosis slows the progression of chronic kidney disease. Curr Opin Nephrol Hypertens. 2019;28:267-77.

65 Nakanishi N, Fukui M, Tanaka M, Toda H, Imai $\mathrm{S}$, Yamazaki $\mathrm{M}$, et al. Low urine $\mathrm{pH}$ Is a predictor of chronic kidney disease. Kidney Blood Press Res. 2012;35:77-81.

66 Jensen T, Abdelmalek MF, Sullivan S, Nadeau KJ, Green M, Roncal C, et al. Fructose and sugar: a major mediator of non-alcoholic fatty liver disease. J Hepatol. 2018;68:1063-75.

67 Johnson RJ, Nakagawa T, Sanchez-Lozada LG, Shafiu M, Sundaram S, Le M, et al. Sugar, uric acid, and the etiology of diabetes and obesity. Diabetes. 2013;62:3307-15.

68 De Cosmo S, Viazzi F, Pacilli A, Giorda C, Ceriello $A$, Gentile $S$, et al. Serum uric acid and risk of CKD in type 2 diabetes. Clin J Am Soc Nephrol. 2015;10:1921-9.

69 Targher G, Chonchol MB, Byrne CD. CKD and nonalcoholic fatty liver disease. Am J Kidney Dis. 2014;64:638-52.

70 Targher G, Francque SM. A fatty liver leads to decreased kidney function? J Hepatol. 2017; 67:1137-9.

71 Zhang J, Xu C, Zhao Y, Chen Y. The significance of serum xanthine oxidoreductase in patients with nonalcoholic fatty liver disease. Clin Lab. 2014;60:1301-7.

72 Loeb JN. The influence of temperature on the solubility of monosodium urate. Arthritis Rheum. 1972;15:189-92.

73 Singh G, Lingala B, Mithal A. Gout and hyperuricaemia in the USA: prevalence and trends. Rheumatology. 2019;58:2177-80.

74 McCarty DJ. Gout without hyperuricemia. JAMA. 1994;271:302-3.

75 Hall AP, Barry PE, Dawber TR, McNamara PM. Epidemiology of gout and hyperuricemia. A long-term population study. Am J Med. 1967;42:27-37.
76 Urano W, Yamanaka H, Tsutani H, Nakajima $\mathrm{H}$, Matsuda Y, Taniguchi A, et al. The inflammatory process in the mechanism of decreased serum uric acid concentrations during acute gouty arthritis. J Rheumatol. 2002; 29:1950-3.

77 Cox CL, Stanhope KL, Schwarz JM, Graham JL, Hatcher B, Griffen SC, et al. Consumption of fructose- but not glucose-sweetened beverages for 10 weeks increases circulating concentrations of uric acid, retinol binding protein-4, and gamma-glutamyl transferase activity in overweight/obese humans. Nutr Metab. 2012;9:68.

78 Clifford AJ, Riumallo JA, Youn VR, Scrimshaw NS. Effect of oral purines on serum and urinary uric acid of normal, hyperuricemic and gouty humans. J Nutr. 1976;106:428-50.

79 DeBosch BJ, Kluth O, Fujiwara H, Schürmann A, Moley K. Early-onset metabolic syndrome in mice lacking the intestinal uric acid transporter SLC2A9. Nat Commun. 2014;5: 4642.

80 Preitner F, Bonny O, Laverrière A, Rotman S, Firsov D, Da Costa A, et al. Glut9 is a major regulator of urate homeostasis and its genetic inactivation induces hyperuricosuria and urate nephropathy. Proc Natl Acad Sci USA. 2009;106:15501-6.

81 Andres-Hernando A, Orlicky DJ, Kuwabara M, Ishimoto T, Nakagawa T, Johnson RJ, et al. Deletion of fructokinase in the liver or in the intestine reveals differential effects on sugarinduced metabolic dysfunction. Cell Metab. 2020;32(1):117-27.e3.

82 Tin A, Marten J, Halperin Kuhns VL, Li Y, Wuttke M, Kirsten $\mathrm{H}$, et al. Target genes, variants, tissues and transcriptional pathways influencing human serum urate levels. Nat Genet. 2019;51:1459-74.

83 Gill D, Cameron AC, Burgess S, Li X, Doherty DJ, Karhunen V, et al. Urate, blood pressure, and cardiovascular disease: evidence from mendelian randomization and meta-analysis of clinical trials. Hypertension. 2021;77(2): 383-92.

84 Kleber ME, Delgado G, Grammer TB, Silbernagel G, Huang J, Kramer BK, et al. Uric acid and cardiovascular events: a mendelian randomization study. J Am Soc Nephrol. 2015; 26(11):2831-8

85 Yan D, Wang J, Jiang F, Zhang R, Wang T, Wang $\mathrm{S}$, et al. A causal relationship between uric acid and diabetic macrovascular disease in Chinese type 2 diabetes patients: a Mendelian randomization analysis. Int J Cardiol. 2016;214:194-9.

86 Ge JY, Ji Y, Zhu ZY, Li X. Genetically elevated serum uric acid and renal function in an apparently healthy population. Urol Int. 2020; 104(3-4):277-82. 